\title{
ПАРАМЕТРИ ВИСОКОЕНЕРГЕТИЧНОГО $\Delta_{1}$-МІНІМУМУ ЗОНИ ПРОВІДНОСТІ $n$-Ge
}

\author{
С. В. Луньов, П. Ф. Назарчук, О. В. Бурбан \\ Луцький національний технічний університет \\ вул. Львівсъка, 75, Луцък, 43018, Украӥна \\ (Отримано 26 жовтня 2012 р.; в остаточному вигляді - 23 липня 2013 р.)
}

\begin{abstract}
На основі експериментальних даних поздовжнього п'єзоопору кристалів $n$-Ge та теорій деформаційного потенціалу й анізотропного розсіяння знайдено комбінацію констант деформаційного потенціалу, ефективну масу густини станів, компоненти тензора ефективної маси для $\Delta_{1}$-мінімуму зони провідності кристалів $n$-Ge. Показано, що характер екранування і відповідно розсіяння змінюється при реалізації в кристалах германію з використанням одновісного тиску вздовж кристалографічного напрямку [100] інверсії типу $\left(L_{1}-\Delta_{1}\right)$ абсолютного мінімуму. Це пояснюється різними значеннями радіуса екранування й екрануючого множника для $L_{1}$ та $\Delta_{1}$-мінімуму.
\end{abstract}

Ключові слова: деформація, п'єзоопір, анізотропія розсіяння.

PACS number(s): 72.20.Fr, 72.10.-d

Сучасний науково-технічний прогрес електронної техніки пов'язаний з освоєнням та розробкою нових матеріалів, які можна використати в різноманітних складних пристроях мікро- та наноелектроніки. Такий напівпровідниковий матеріал, як германій, незважаючи на всебічну вивченість його властивостей, і надалі є перспективним матеріалом для створення різних приладів та сенсорів. В екстремальних умовах дії значних зовнішніх електричних, деформаційних, оптичних та температурних полів участь у різних кінетичних та оптичних ефектах можуть брати не лише мінімуми зони провідності кристалів германію із симетрією $L_{1}$, а також високоенергетичні мінімуми $\Gamma_{2}$, $\Delta_{1}$ та $\Gamma_{15}$. Наприклад, радикальну перебудову зонної будови кристалів $n$-Ge 3 домінуючим внеском $\Delta_{1}-$ мінімуму, який є вище за шкалою енергій на $0.18 \mathrm{eB}$ від $L_{1}$-мінімуму, можна реалізувати при сильних гідростатичних або одновісних тисках. Це своєю чергою відкриває перспективи для створення на основі германію різних електронних приладів та датчиків, які можуть працювати в таких екстремальних умовах. Зокрема в роботі [1] виявлено різке зростання інтенсивності екситонного поглинання в кристалах германію при гідростатичному тиску, більшому від 0.6 ГПа, що може бути використано у фотодетекторах.

Дослідження різних кінетичних ефектів у сильно деформованих кристалах $n$-Ge є актуальним також 3 погляду вивчення властивостей наноструктур. Як показує літературний огляд сучасних праць, в наноструктурах із компонентою германію виникає гігантське збільшення рухливості порівняно з недеформованими кристалами $n$-Ge та $n$-Si, яке має широке практичне використання в CMOS-приладах [2, 3]. Висока рухливість електронів дає змогу також створювати транзистори з високопровідними каналами $[4,5]$. Час перемикання таких транзисторів може становити пікосекунди. Така значна зміна рухливості пов'язана з суттєвою деформаційною перебудовою зонної структури кристалів германію за рахунок значних внут- рішніх напруг, які виникають у цих наноструктурах. Прикладом напруженого германію є також гетерострукутури $\mathrm{Si} / \mathrm{Ge}$. У таких наноструктурах кластери германію є пружно деформованими, оскільки параметри кристалічних граток германію та кремнію відрізняються приблизно на 4 відсотки [6]. Використання наноструктур із самоіндукованими $\mathrm{Ge} / \mathrm{Si}$ наноострівцями відкриває нові перспективи для розвитку оптота наноелектроніки [7]. Масиви $\mathrm{Ge}(\mathrm{GeSi})$ квантових точок з успіхом можна застосувати для виготовлення фотодетекторів для ближнього інфрачервоного діапазону та світловипромінювальних діодів для цієї ж спектральної області, оскільки вони мають певні переваги над традиційними $\mathrm{Ge} / \mathrm{Si}$ структурами з квантовими ямами [8]. Просторове впорядкування таких наноострівців залежить також від розподілу деформаційних полів у цих наноструктурах [9]. Однією 3 основних проблем при заданих необхідних електрофізичних властивостях таких наноструктур є якраз урахування впливу деформацій на кількісні характеристики шарів цих наноструктур, зокрема таких, як співвідношення товщин яма-бар'єр, розподіл компонентного складу, процеси дифузії [10].

Для кількісного трактування фізичних явищ при кардинальній перебудові зонного спектра матеріалу необхідно мати параметри активних енергетичних мінімумів зони провідності, одними з яких є ефективна маса й компоненти тензорів ефективної маси та деформаційного потенціалу.

На сьогодні відомі поодинокі роботи з розрізненими даними щодо значень компонент тензора ефективної маси, параметра анізотропії ефективних мас та комбінації констант деформаційного потенціалу для $\Delta_{1}$ мінімумів в $n$-Ge [11-13]. Спільним для цих праць є те, що остаточний результат отриманий на основі використання даних неспоріднених досліджень інших авторів, що може вносити додаткові похибки в значення шуканих параметрів.

Тому ми дослідили ефект поздовжнього п'єзоопору 
в кристалографічному напрямку [100] для легованих сурмою до рівня $n=2.0 \cdot 10^{18} \mathrm{~cm}^{-3}$ монокристалів германію в ділянці виключно йонного розсіювання носіїв заряду $(T=4.2 \mathrm{~K})$. Результати експерименту, які використовували в розрахунках, показані на рис. 1.

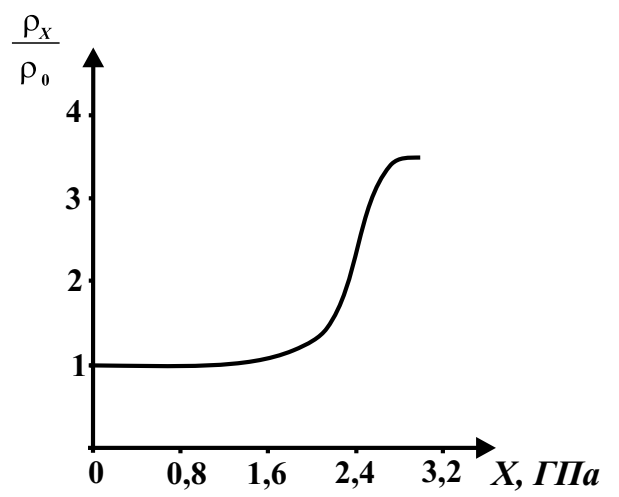

Рис. 1. Залежність поздовжнього п'єзоопору $n$-Ge〈Sb $\rangle$ від величини одновісного тиску вздовж кристалографічного напрямку $\langle 100\rangle$ при $T=4.2 \mathrm{~K}$.

При деформації вздовж кристалографічного напрямку [100] чотири $L_{1}$-долини зміщуватимуться вгоpy, а дві $\Delta_{1}$-долини вниз за шкалою енергій. Тоді питому електропровідність деформованого зразка можна записати у вигляді:

$$
\sigma=e\left(4 n_{L} \mu_{L}+2 n_{\Delta} \mu_{\Delta}\right)
$$

Тут індексами $L$ та $\Delta$ позначено параметри відповідних енергетичних мінімумів. Крім того, $4 n_{L}+$ $2 n_{\Delta}=n_{e}=2 \cdot 10^{18} \mathrm{~cm}^{-3}=$ const для будь-якої точки кривої п'єзоопору. Сумісний розв'язок цих співвідношень дає роздільну концентрацію електронів у відповідних долинах:

$$
n_{L}=\frac{\sigma-n_{e} \mu_{\Delta} e}{4 e\left(\mu_{L}-\mu_{\Delta}\right)}, \quad n_{\Delta}=\frac{n_{e} \mu_{L} e-\sigma}{2 e\left(\mu_{L}-\mu_{\Delta}\right)}
$$

Статистика електронного газу в долинах така, що для області початкового зростання питомого опору кристала з тиском в $L_{1}$-мінімумах він є виродженим, а в $\Delta_{1}$-мінімумах - невиродженим. Для області насичення ситуація змінюється на протилежну, причому саме плато залежності означає повну відсутність електронів в $L_{1}$-мінімумах. Тому аналітичні залежності концентрацій електронів в $L_{1}$ - і $\Delta_{1}$-мінімумах визначатимуться як

$$
\begin{aligned}
& n_{L}=\frac{8 \pi}{3}\left(\frac{2 m_{L}}{\hbar^{2}}\right)^{\frac{3}{2}}\left(E_{\mathrm{F}}-E_{L}\right)^{\frac{3}{2}}, \\
& n_{\Delta}=N_{C} \exp \left(\frac{E_{\mathrm{F}}-E_{\Delta}}{k T}\right),
\end{aligned}
$$

де $E_{\mathrm{F}}, E_{L}, E_{\Delta}$ - енергї̈ Фермі та відповідних мінімумів деформованого кристала відносно нульового рів- ня, яким є енергетичне положення дна зони провідності недеформованого кристала й позначається індексом " 0 "; $N_{C}=2\left(\frac{2 \pi m_{\Delta} k T}{h^{2}}\right)^{\frac{3}{2}}$ - ефективна густина енергетичних станів для $\Delta_{1}$-мінімуму. 3 наведених виразів для концентрацій носіїв заряду можна знайти енергетичне положення рівня Фермі та зміщення дна $\Delta_{1}$-мінімуму як функції величини одновісного тиску:

$$
\begin{gathered}
E_{\mathrm{F}}=\left(\frac{3}{8 \pi}\right)^{\frac{2}{3}} \frac{\hbar^{2}}{2 m_{L}}\left(\frac{\sigma-n_{e} \mu_{\Delta} e}{4 e\left(\mu_{L}-\mu_{\Delta}\right)}\right)^{\frac{2}{3}}+\Delta E_{L} \\
\Delta E_{\Delta}=-\left(E_{\Delta_{0}}-E_{L_{0}}\right)+\Delta E_{L}+k T \ln N_{C} \\
-k T \ln \frac{n_{e} \mu_{L} e-\sigma}{2 e\left(\mu_{L}-\mu_{\Delta}\right)}+\left(\frac{3}{8 \pi}\right)^{\frac{2}{3}} \frac{\hbar^{2}}{2 m_{L}}\left(\frac{\sigma-n_{e} \mu_{\Delta} e}{4 e\left(\mu_{L}-\mu_{\Delta}\right)}\right)^{\frac{2}{3}} .
\end{gathered}
$$

Тут $\Delta E_{L}$ - деформаційне зміщення $L_{1}$-мінімуму; $\left(E_{\Delta_{0}}=0.18 \mathrm{eB}\right.$, a $\left.E_{L_{0}}=0\right)$.

Для обчислення зміни положення $\Delta_{1}$-мінімуму при одновісному тиску потрібно використати всі відомі й надійно встановлені параметри $L_{1}$-мінімуму та значення констант жорсткості для кристалів германію:

$$
\begin{aligned}
& \Xi_{u}^{L}=16.4 \mathrm{eB}, \quad \Xi_{d}^{L}=-6.4 \mathrm{eB}, \\
& S_{11}=0.769 \cdot 10^{-11} \Pi \mathrm{a}^{-1}, \quad S_{12}=-0.21 \cdot 10^{-11} \Pi^{-1} .
\end{aligned}
$$

Величини $\mu_{L}=780 \mathrm{~cm}^{2} / \mathrm{Bc}$ і $\mu_{\Delta}=220 \mathrm{~cm}^{2} / \mathrm{Bc}$ можна знайти за відомими значеннями концентрації носіїв струму та провідності недеформованого й сильно деформованого кристала (плато експериментальної залежності).

Як показують відповідні розрахунки, згідно з (5), зміщення $\Delta E_{\Delta}$ дна $\Delta_{1}$-мінімуму добре апроксимується лінійною функцією тиску, що також узгоджується з теорією деформаційного потенціалу [14], використовуючи яку, деформаційне зміщення двох $\Delta_{1}$ мінімумів можна записати у вигляді:

$$
\Delta E_{\Delta}=-\alpha X
$$

де

$$
\begin{gathered}
\alpha=\left(\Xi_{d}^{\Delta}+\frac{1}{3} \Xi_{u}^{\Delta}\right)\left(S_{11}+2 S_{12}\right) \\
+\frac{2}{3} \Xi_{u}^{\Delta}\left(S_{11}-S_{12}\right)=\text { const. }
\end{gathered}
$$

Ураховуючи вирази (5) та (6), можна знайти комбінацію констант деформаційного потенціалу для $\Delta_{1}$-мінімуму: $0.35 \Xi_{d}^{\Delta}+0.77 \Xi_{u}^{\Delta}=8.65 \mathrm{eB}$.

Для довільних значень одновісного тиску $X_{1}, X_{2}, \ldots, X_{n}$, згідно з (5) та (6):

$\frac{\Delta E_{\Delta}\left(X_{1}\right)}{X_{1}}=\frac{\Delta E_{\Delta}\left(X_{2}\right)}{X_{2}}=\ldots=\frac{\Delta E_{\Delta}\left(X_{n}\right)}{X_{n}}=$ const.

Тоді, враховуючи (5) та (7), 


$$
\begin{aligned}
& \frac{1}{X_{1}}\left(-\left(E_{\Delta_{0}}-E_{L_{0}}\right)+\Delta E_{L}\left(X_{1}\right)+k T \ln N_{C}-k T \ln \frac{n_{e} \mu_{L} e-\sigma\left(X_{1}\right)}{2 e\left(\mu_{L}-\mu_{\Delta}\right)}+\left(\frac{3}{8 \pi}\right)^{\frac{2}{3}} \frac{\hbar^{2}}{2 m_{L}}\left(\frac{\sigma\left(X_{1}\right)-n_{e} \mu_{\Delta} e}{4 e\left(\mu_{L}-\mu_{\Delta}\right)}\right)\right. \\
& =\frac{1}{X_{2}}\left(-\left(E_{\Delta_{0}}-E_{L_{0}}\right)+\Delta E_{L}\left(X_{2}\right)+k T \ln N_{C}-k T \ln \frac{n_{e} \mu_{L} e-\sigma\left(X_{2}\right)}{2 e\left(\mu_{L}-\mu_{\Delta}\right)}+\left(\frac{3}{8 \pi}\right)^{\frac{2}{3}} \frac{\hbar^{2}}{2 m_{L}}\left(\frac{\sigma\left(X_{2}\right)-n_{e} \mu_{\Delta} e}{4 e\left(\mu_{L}-\mu_{\Delta}\right)}\right) .\right.
\end{aligned}
$$

Розв'язок рівняння (8) з урахуванням експериментальних значень питомих електропровідностей $\sigma\left(X_{1}\right)$ та $\sigma\left(X_{2}\right)$ початкового зростання залежності питомого опору від одновісного тиску (див. рис. 1) дає таке значення ефективної маси густини станів електронів для $\Delta_{1}$-мінімуму: $m_{\Delta}=0.88 m_{0}$. Залежність енергії електрона $E$ від хвильового вектора $\mathbf{k}$ як для $L_{1}$, так i $\Delta_{1}$-мінімуму має вигляд еліпсоїда обертання. Тому

$$
m_{\Delta}=\left(m_{\|} m_{\perp}^{2}\right)^{\frac{1}{3}},
$$

де $m_{\|}, m_{\perp}-$ поздовжній та поперечний складник ефективної маси електрона для $\Delta_{1}$-мінімуму відповідно.

Оскільки таких еквівалентних $\Delta_{1}$-еліпсоїдів при інверсії типу $\left(L_{1}-\Delta_{1}\right)$ абсолютного мінімуму, зумовленої одновісним тиском кристалів $n$-Ge вздовж кристалографічного напрямку [100], буде не 1, а 2, то ефективна маса густини станів

$$
\begin{aligned}
m_{\Delta}^{*} & =N^{\frac{2}{3}}\left(m_{\|} m_{\perp}^{2}\right)^{\frac{1}{3}}=2^{\frac{2}{3}}\left(m_{\|} m_{\perp}^{2}\right)^{\frac{1}{3}} \\
& =2^{\frac{2}{3}} m_{\Delta}=0.88 m_{0} .
\end{aligned}
$$

Якщо ізоенергетичні поверхні є еліпсоїдами обертання, то рухливість носіїв заряду в довільному на- прямку визначається зі співвідношення [15]

$$
\mu=\mu_{\perp} \sin ^{2} \theta+\mu_{\|} \cos ^{2} \theta
$$

де $\theta-$ кут між розгляданим напрямком і головною віссю еліпсоїда; $\mu_{\perp}$ і $\mu_{\|}-$рухливість носіїв заряду поперек і вздовж осі еліпсоїда. Для випадку, коли одновісний тиск $X$ та струм $J$ направлені вздовж кристалографічного напрямку [100], то, згідно з (10), для $\Delta_{1}$-мінімуму

$$
\begin{gathered}
\mu_{\Delta}=\mu_{\|}^{\Delta}=\frac{e}{m_{\|}^{\Delta}}\left\langle\tau_{\|}^{\Delta}\right\rangle, \\
\left\langle\tau_{\|}\right\rangle=\frac{4}{3 \sqrt{\pi}} \int_{0}^{\infty} d x x^{\frac{3}{2}} e^{-x} \tau .
\end{gathered}
$$

На основі теорії анізотропного розсіяння запишемо вираз для поздовжньго складника $\tau_{\|}$тензора часів релаксації в умовах розсіяння на йонах домішки [16]:

$$
\tau_{\|}=\frac{1}{\lambda}
$$

$$
\lambda=2 C\left(\frac{\pi-2 \chi}{2} \ln \frac{\beta \rho+1}{\beta \rho-1}-\left(2 \alpha+\frac{\pi}{2}\right) \ln 2+L(\chi+\alpha)-L(\chi-\alpha)+L\left(\frac{\pi}{2}-2 \alpha\right)+2 L(\alpha)-\frac{\beta}{1+\beta^{2}} \ln (b+1)\right)
$$

де $C=\frac{3 \pi n_{e} e^{4} \sqrt{2 m_{\|}}}{8 \beta^{3} \varepsilon^{2} m_{\perp}(k T)^{\frac{3}{2}} x^{\frac{3}{2}}}, \rho=\frac{1}{\beta} \sqrt{1+\frac{1+\beta^{2}}{b}}, \beta^{2}=\frac{m_{\|}-m_{\perp}}{m_{\perp}}, \chi=\arctan \rho, \alpha=\arctan \beta, L(y)=-\int_{0}^{y} \ln \cos \varphi d \varphi$ - функція Лобачевського, $N=n_{e}-$ концентрація домішки, $\varepsilon-$ діелектрична проникність (для германію $\varepsilon=16)$.

Тут $b=\frac{8 m^{*} \bar{E}}{\hbar^{2}} R_{0}^{2}, \bar{E}=k T \frac{\Phi_{\frac{3}{2}}\left(E_{\mathrm{F}}^{*}\right)}{\Phi_{\frac{1}{2}}\left(E_{\mathrm{F}}^{*}\right)}-$ середня енергія електронів;

$x=\frac{E-\Delta E_{\Delta}}{k T}, E_{\mathrm{F}}^{*}=\frac{E_{\mathrm{F}}}{k T}, \Phi_{n}=\int_{0}^{\infty} \frac{x^{n} d x}{e^{x-E}+1}-$ інтеграли Фермі, $R_{0}$ - радіус екранування, який у найзагальнішому вигляді визначається так [16]:

$$
R_{0}^{2}=\frac{h^{3} \varepsilon}{16 \pi^{2} e^{2}\left(m^{*}\right)^{\frac{3}{2}}(2 k T)^{\frac{1}{2}} \Phi_{-\frac{1}{2}}\left(E_{\mathrm{F}}^{*}\right)} .
$$

$\mathrm{У}$ результаті можна отримати систему рівнянь щодо невідомих значень компонент тензора ефективної ма- си $m_{\|}, m_{\perp}$ :

$$
\left\{\begin{array}{l}
\left(m_{\|} m_{\perp}^{2}\right)^{\frac{1}{3}}=m_{\Delta} \\
\frac{4 e}{3 \sqrt{\pi} m_{\|}} \int_{0}^{\infty} d x x^{\frac{3}{2}} \tau_{\|}=\mu_{\Delta} .
\end{array}\right.
$$

Ураховуючи вирази (4), (5), (13) та значення ефективної маси густини станів $m_{\Delta}$ та рухливості електронів $\mu_{\Delta}$ для $\Delta_{1}-$ мінімуму, які наведені вище, обчислено $m_{\|}=1.65 m_{0}$ та $m_{\perp}=0.32 m_{0}$.

Для напівпровідникових кристалів із концентрацією носіїв заряду $n_{e} \geq 10^{16} \mathrm{~cm}^{-3}$ суттєвими стають 
ефекти екранування [17]. Тому для теоретичного опису різноманітних явищ переносу в сильно легованих кристалах поряд із такими важливими параметрами, як ефективна маса, компоненти тензора ефективної маси й деформаційного потенціалу, необхідно мати також відомості про величину радіуса екранування та екрануючого множника [18]:

$$
g(b)=\ln (1+b)-\frac{b}{1+b} .
$$

Із виразу (14) видно, що існує сильна залежність довжини екранування від ефективної маси густини станів. Саме ця обставина змушує звернути увагу на поведінку величини радіуса екранування при реалізації інверсії типу $\left(L_{1}-\Delta_{1}\right)$ абсолютного мінімуму в $n$-Ge , оскільки названий параметр суттєво впливає на розсіяння носіїв заряду кулонівськими центрами i при певних умовах визначає енергетичний спектр локальних рівнів домішки [19].

Для визначення радіуса екранування та екрануючого множника для $L_{1}$ і $\Delta_{1}$-мінімуму необхідно обчислити інтеграли Фермі індексів $\frac{1}{2},-\frac{1}{2}, \frac{3}{2}$, а для цього спочатку треба знайти положення рівня Фермі стосовно дна зони провідності відповідного мінімуму зі співвідношення:

$$
n_{e}=\frac{2 N_{\mathrm{C} i}}{\sqrt{\pi}} \Phi_{\frac{1}{2}}\left(E_{\mathrm{F} i}^{*}\right),
$$

де $N_{\mathrm{C} i}, E_{\mathrm{F} i}^{*}-$ ефективна густина станів та зведене значення енергіï Фермі для $i$-ого мінімуму. Враховуючи значення ефективної маси густини станів для $L_{1}$ i $\Delta_{1}$-мінімуму, обчислено для концентрації домішки $n_{e}=2 \cdot 10^{18} \mathrm{~cm}^{-3}$ при $T=4.2 \mathrm{~K}$ енергетичні положення рівня Фермі: $E_{\mathrm{F}}^{L_{1}}=10.5 \mathrm{eB}$ та $E_{\mathrm{F}}^{\Delta_{1}}=6.6 \mathrm{eB}$. Значення радіуса екранування та екрануючого множника для $L_{1}$ і $\Delta_{1}$-мінімуму виявилися рівними: $R_{0}^{L_{1}}=$ $1.76 \cdot 10^{-7} \mathrm{~cm}, g_{L_{1}}(b)=0.227$ та $R_{0}^{\Delta_{1}}=1.41 \cdot 10^{-7} \mathrm{~cm}$, $g_{\Delta_{1}}(b)=0.127$. Різна величина радіуса екранування та екрануючого множника для $L_{1}$ і $\Delta_{1}$-мінімуму зони провідності кристалів $n$-Ge вказують на різний характер екранування й відповідно розсіяння електронів для різних типів мінімумів.

Таким чином, використовуючи теорії деформаційного потенціалу й анізотропного розсіяння та лише дані експерименту з визначення величини поздовжнього п'єзоопору на ділянці одновісних тисків, коли починається "деформаційне підмішування" енергетичних станів $\Delta_{1}$-мінімуму, можна досить надійно визначити:

1. Комбінацію констант деформаційного потенціалу для цього мінімуму.

2. Ефективну масу густини станів.

3. Компоненти тензора ефективної маси.

4. Радіус екранування та екрануючий множник.
[1] G. H. Li, A. R. Goni, K. Syassen, M. Cardona, Phys. Rev. B 49, 8017 (1994).

[2] F. Murphy-Armando, S. Fahy, J. Appl. Phys. 109, 113703 (2011).

[3] B. Lemke, R. Baskaran, O. Paul, Sens. Actuat. A 176 , 10 (2012).

[4] Y. S. Choi, J.-S. Lim, T. Numata, T. Nishida, E. S. Thompson, J. Appl. Phys. 102, 104507 (2007).

[5] M. Kobayashi et al., IEEE Trans. Electron Dev. 57, 1037 (2010).

[6] K. Brunner, Rep. Prog. Phys. 65, 27 (2002).

[7] Д. Н. Дроздов и др., Физ. техн. полупр. 43, 332 (2009).

[8] S. Tong, J. Liu, L. J. Wan, K. L. Wang, Appl. Phys. Lett. 80, 1189 (2002).

[9] В. О. Юхимчук та ін., Укр. фіз. журн. 56, 254 (2011).

[10] А. Н. Ефанов и др., Металлофиз. нов. технол. 28, 441 (2006).
[11] П. И. Баранский В. В. Коломоец, Б. Н. Сусь, В. И. Шаповалов, Физ. техн. полупр. 13, 602 (1979).

[12] T. Arizumi, A. Yoshida, N. Savaki, J. Appl. Phys. Jpn 8, 700 (1969).

[13] В. В. Байдаков $и$ др., Физ. техн. полупр. 17, 370 (1983).

[14] C. Herring, E. Vogt, Phys. Rev. 101, 944 (1956).

[15] Г. Л. Бир, Симметрия и деформачионные эффекты в полупроводниках (Наука, Москва, 1972).

[16] В. И. Фистуль, Сильно легированные полупроводники (Наука, Москва, 1967).

[17] Я. С. Буджак, О. В. Зуб, Вост.-Европ. журн. передов. технол. 53, 11 (2011).

[18] Б. Г. Журкин, В. С. Земсков, К. В. Юркина, Физ. тверд. тела 3, 3509 (1961).

[19] В. Л. Бонч-Бруевич, С. Г. Калашников, Физика полупроводников (Наука, Москва, 1977). 


\title{
PARAMETERS OF THE HIGH-ENERGY $\Delta_{1}$-MINIMUM OF THE CONDUCTION BAND IN $n$-Ge
}

\author{
S. V. Luniov, P. F. Nazarchuk, O. V. Burban \\ Lutsk National Technical University, Physics and Electrical Engineering Depart., \\ 75 Lvivska Avenue, Lutsk, UA-43018, Ukraine \\ e-mail: luniovser@mail.ru
}

\begin{abstract}
On the basis of longitudinal piezoresistance experiments in the $n$-Ge crystals using the theory of deformation potential and the theory of anisotropic scattering the combination deformation potential constants, effective mass of the density of states, effective mass tensor components for $\Delta_{1}$-minimum conduction band of $n$-Ge are defined. It is shown that the screening effect and scattering vary as a result of the realized $\left(L_{1}-\Delta_{1}\right)$ absolute minimum type inversion in crystals of germanium about unaxial pressure along the crystallographic direction [100]. That was explained by different values of the screening radius as a screening factor for $L_{1}$ and $\Delta_{1}$-minimum.
\end{abstract}

